\title{
Spending with unnecessary complementary tests for hypertension and diabetes in health services
}

\author{
Gastos com exames complementares desnecessários \\ para hipertensos e diabéticos nos serviços de saúde \\ Gastos con pruebas de laboratorio para hipertensos \\ y diabéticos en los servicios de salud
}

\author{
Thiago Roberto Castellane Arena ${ }^{\mathrm{a}}$ \\ Marli de Carvalho Jericób \\ Liliana Cristina de Castroc \\ Valéria Castilho ${ }^{d}$ \\ Antonio Fernandes Costa Lima ${ }^{e}$
}

\begin{abstract}
The aims of this study were to analyze unnecessary laboratory exams for patients with hypertension and diabetes and to check the expenditures involved. This is an exploratory-descriptive, cross-sectional study with a quantitative approach. We used data from medical records of 293 patients registered in primary units - the Family Health Center (NSF3); secondary: School Health Center (CSE); and tertiary: Hospital das Clínicas (HC) from 2006 to 2009 in a city in Southeastern Brazil. We identified a total of 9,522 laboratory tests, of which 5.97\% were unnecessary. Of these, about $58 \%$ were requested by NSF3 and $42 \%$ by CSE. Results suggest there is a lack of integration among different levels of health care, which result in misallocation of resources and unnecessary spending.

Descriptors: Health expenditures. Hypertension. Diabetes mellitus. Family health. Health services.
\end{abstract}

\section{RESUMO}

Este estudo objetivou analisar a solicitação e os gastos com exames complementares desnecessários para pacientes hipertensos e diabéticos nos serviços de saúde. Trata-se de estudo transversal retrospectivo, utilizando dados de prontuários de 293 pacientes cadastrados nas unidades de níveis primário - Núcleo de Saúde da Família (NSF3), secundário - Centro de Saúde Escola (CSE) e terciário - Hospital das Clínicas (HC), no período de 2006 a 2009 em um município da região sudeste do Brasil. Observou-se um total de 9.522 exames laboratoriais totalizando R\$28.208,28, sendo 568 (5,97\%) desnecessários - R\$1.641,58. Destes, cerca de R\$952,12 (58\%) foram solicitados pela NSF3, e R\$689,46(42\%), pelo CSE. Os resultados sugerem que ocorre falta de integração nos diferentes níveis de atenção à saúde, acarretando má alocação de recursos e gastos desnecessários.

Descritores: Gastos em saúde. Hipertensão. Diabetes mellitus. Saúde da família. Serviç̧os de saúde.

\section{RESUMEN}

El objetivo del estudio fue analizar la solicitación y los gastos con exámenes auxiliares innecesarios para pacientes con hipertensión y diabetes en los servicios de salud. Se trata de un estudio transversal retrospectivo, utilizando datos de las historias clínicas de 293 pacientes registrados en las unidades de niveles primario -el Núcleo de Salud de la Familia (NSF3), secundario- Centro de Salud de la Escuela (CSE) y terciario Hospital de Clínicas (HC), en el período de 2006 a 2009 en una ciudad del sudeste de Brasil. Hubo un total de 9.522 exámenes de laboratorio, de los cuales un 5,97\% innecesarios. De estos, cerca del 58\% fue solicita por el NSF3 y el 42\% en el CSE. LOS resultados sugieren que ocurre falta de integración entre los diferentes niveles de atención de salud, causando mala distribución de recursos y gastos innecesarios.

Descriptores: Gastos en salud. Hipertesión. Diabetes mellitus. Salud de la familia. Servicios de salud.
DOl: $\quad$ http://dx.doi.org/10.1590/1983-

1447.2014.04.44793 


\section{口INTRODUCTION}

Chronic non-communicable diseases (CNCDs), such as systemic arterial hypertension (SAH) and diabetes mellitus (DM), are one of the biggest challenges for health services, due to the high rates of morbimortality that are threatening the quality of life of millions of people (carriers for the disease, family, society) and increasing the costs for health systems around the world ${ }^{(1)}$.

Within the next decades, it is believed that the cost of CNCDs could reach $\$ 7$ trillion dollars in the United States, and in Brazil, it would account for $4 \%$ of the GDP(2). Given this situation, actions of prevention, diagnosis and early treatment, especially for SAH and DM, must be considered a priority by health services.

According to the International Diabetes Federation, the total of patients with DM was 371 million around the world in 2012, which resulted in 4.8 million deaths and spending reaching $\$ 471$ billion dollars ${ }^{(3)}$.

In this context, Brazil is among the ten countries with the highest number of DM patients aged between 20 and 79, totaling 13.4 million of diabetic people in 2012, with an average cost of US\$1,031.44 per patient ${ }^{(3)}$.

Systemic arterial hypertension is considered both a disease and a risk factor for cardiovascular, cerebrovascular and renal diseases. It is responsible for $51 \%$ of deaths resulting from cerebrovascular diseases and $41 \%$ of coronary diseases. It is estimated that SAH will affect $60 \%$ of people by 2025 , reaching an incidence of $40 \%$. (4) This increase in hypertension incidence is attributed to population growth, aging, and behavior-based risk factors such as inadequate diet, alcohol abuse, sedentary lifestyle, obesity, stress, smoking, high cholesterol and diabetes mellitus. Moreover, a high number of cases is not properly treated, which contributes to the occurrence of several complications, such as target organ injuries - cerebral vascular accident, acute myocardial infarction, chronic renal failure, and hypertensive retinopathy - which contribute to the increase of costs related to hypertension. ${ }^{(5)}$

A Brazilian study conducted between January and December 2005 reported the Unified Health System (SUS, as per its acronym in Portuguese) spent \$398.9 million dollars with SAH treatment. Of this total, spending with medication corresponded to 52.3\% (208 million dollars), followed by medical consultations (20.6\% - \$ 82.5 million dollars) and complementary exams (16.5\% - 65.9 million dollars)(5).
Although there are many preventive strategies with the aim to reduce the incidence of risk factors for CNCDs, these strategies have presented low effectiveness due to the difficulty to get access to the health system, limited availability of complementary exams and medications, as well as the sociodemographic, cultural and epidemiological characteristics of the Brazilian population ${ }^{(6)}$.

Given this situation, trying to control CNCDs, more specifically SAH and DM, is a major challenge for the Family Health Strategy (FHS), which has to develop health policies based on clinical-epidemiological evidence in order to ensure efficient treatment and to reduce the number and severity of potential complications that increase socioeconomic costs.

In Brazil, $80 \%$ of people depend on the public health system and $20 \%$ can rely only on the private health system ${ }^{(5)}$; in this sense, economic and epidemiological analyses are covered by health services.

The aims of the present study were to analyze the requests and expenditures with unnecessary complementary exams for hypertensive and diabetic patients in health services.

\section{$\square$ METHODS}

This is a cross-sectional retrospective study carried out in four year-period (2006-2009). It was conducted in the Family Health Unit (NSF3, as per its acronym in Portuguese) - primary level, Health Center School (CSE, as per its acronym in Portuguese) - secondary level, and at Hospital das Clínicas (HC) - tertiary level, all of which are associated with the Ribeirão Preto College of Nursing. The research proposal was approved by the Research Ethics Committee of the Health Center of the School of Medicine of Ribeirão Preto - USP (protocol 274/2009).

Of the total 455 patients registered in NSF3, according to data from the Primary Care Information System (SIAB, as per its acronym in Portuguese) of May 12th 2008, 287 patients with SAH and/or DM participated in the study, of which 134 were treated in the NFS3, and the others used more than one service in the aforementioned period (71 patients used NFS3 and CSE; 3434 patients used NHC; 48 and HC, 48 patients used NSF3, (SE and $\mathrm{HC}$ ).

Inclusion criteria were: being duly registered at NSF3; having SAH (SAP equal or greater than $140 \mathrm{mmHg}$ and/or DAP equal or greater than $90 \mathrm{mmHg}$ ) and/or DM (8-12 hour fasting blood glucose greater than $126 \mathrm{mg} / \mathrm{dL}$ or post-prandial blood glucose greater than $200 \mathrm{mg} / \mathrm{dL}^{(7)}$. 
Chart 1. Routine of laboratory tests for patients with hypertension and diabetes in the city of Ribeirão Preto, 2006.

\begin{tabular}{|c|c|c|}
\hline \multicolumn{3}{|c|}{$\begin{array}{l}\text { Routine of laboratory test requested for patients with hypertension } \\
\text { and diabetes in the city of Ribeirão Preto (2006) }\end{array}$} \\
\hline $\begin{array}{l}\text { Tests to be requested annually for } \\
\text { patients with hypertension and/or } \\
\text { diabetes }\end{array}$ & $\begin{array}{c}\text { Urea } \\
\text { Creatinine } \\
\text { Uric acid } \\
\text { Sodium } \\
\text { Potassium } \\
\text { Total cholesterol } \\
\text { Triglyceride } \\
\text { High Density Lipoprotein (HDL) }\end{array}$ & $\begin{array}{l}\text { Fasting blood glucose } \\
\text { Routine urine } \\
\text { Sodium } \\
\text { Microalbuminuria* } \\
\text { Electrocardiogram (ECG) } \\
\text { Chest radiography } \\
\text { Fundus oculi }\end{array}$ \\
\hline $\begin{array}{l}\text { Tests to be requested with quarterly } \\
\text { frequency for diabetics with fasting } \\
\text { blood glucose control } \leq 126 \mathrm{mg} / \mathrm{dL}\end{array}$ & \multicolumn{2}{|c|}{$\begin{array}{c}\text { Fasting blood glucose } \\
\text { Post-prandial blood glucose } \\
\text { Glycohemoglobin }\end{array}$} \\
\hline $\begin{array}{l}\text { Tests to be requested annually for } \\
\text { patients with type } 1 \text { diabetes and, if } \\
\text { necessary for type } 2\end{array}$ & \multicolumn{2}{|c|}{ Thyroid Stimulating Hormone (TSH) } \\
\hline
\end{tabular}

Source: research data.

For data collection, individual forms were used in each patient, including data regarding identification details, physical examination, medication, laboratory tests performed, record of diagnosis within the period and related complications.

The analyzed information in the project scope was related to routine laboratory tests performed with patients with $\mathrm{SAH}$ and DM, as defined by the protocol of the Municipal Health Secretariat (SMS, as per its acronym in Portuguese) of Ribeirão Preto, which is shown in Chart 1.

For filling the forms regarding blood and/or urine laboratory tests, all notes from laboratory tests performed for each patient from 2006 to 2009 were considered.

For statistical analysis and conclusion, all the necessary conversions of laboratory test figures were made when they had different units of measure.

An "unnecessary" classification was given to all tests of the same type, for the same patient, on close dates and in duplicate, requested by different health units, and which did not respect the frequecy established by the SMS of Ribeirão Preto.
The Unified Health System costs table was used, as per resolution 10/2009 of the Management System of the List of Procedures, Drugs, Prosthesis and Synthetic Materials (SIGTAP/DATASUS) in order to evaluate the costs of complementary exams.

Data were organized in the form of descriptive statistical figures (absolute and relative frequencies) by means of the 2002 Microsoft Excel ${ }^{\circ}$ software and the amounts were expressed in Reais, the Brazilian currency.

\section{RESULTS}

In this study, there was a prevalence of female patients (mean of $60 \%$ ) at the three levels of care, with a lower rate among people aged over 45 years old (mean of $5.7 \%$ ), and a significant rate among people aged over 65 years old (55\%).

The percentage of care services provided was 60\% for women at all levels (NSF3, CSE and HC).

Data were obtained from 293 hypertensive and/or diabetic registered patients.

Regarding their clinical profile (Table 1), there was a greater incidence of patients with SAH at the three levels of care. 
Table 1. Patients' clinical profile according to the level of treatment $(n=496)$, between 2006 and 2009. Ribeirão Preto, São Paulo, Brazil, 2010.

\begin{tabular}{lcccccc}
\multirow{2}{*}{ Initial diagnoses } & \multicolumn{2}{c}{ NSF3 } & \multicolumn{3}{c}{ CSE } & \multicolumn{3}{c}{ HC } \\
\cline { 2 - 7 } & $\mathbf{N}$ & $\mathbf{N}$ & $\mathbf{N}$ & $\mathbf{\%}$ & $\mathbf{N}$ & $\%$ \\
\hline SAH & 173 & 60.3 & 57 & 46.7 & 50 & 57.5 \\
DM & 22 & 7.6 & 16 & 13.1 & 10 & 11.5 \\
DM + SAH & 92 & 32.1 & 49 & 40.2 & 27 & 31 \\
\hline Total & $\mathbf{2 8 7}$ & $\mathbf{1 0 0}$ & $\mathbf{1 2 2}$ & $\mathbf{1 0 0}$ & $\mathbf{8 7}$ & $\mathbf{1 0 0}$ \\
\hline
\end{tabular}

Source: research data.

NSF3 - Family Health Unit; CSE - Health Center School; HC - Hospital das Clínicas; SAH - Systemic Arterial Hypertension; DM - Diabetes Mellitus.

Table 2. Patients according to the association of places of treatment ( $n=293$ ), between 2006 and 2009. Ribeirão Preto, São Paulo, Brazil, 2010.

\begin{tabular}{|c|c|c|c|c|c|c|c|c|c|c|c|c|c|c|c|}
\hline & \multicolumn{2}{|c|}{ NSF3 } & \multicolumn{2}{|c|}{ CSE } & \multicolumn{2}{|c|}{$\mathrm{HC}$} & \multicolumn{2}{|c|}{$\mathrm{NSF} 3+\mathrm{CSE}$} & \multicolumn{2}{|c|}{ CSE + HC } & \multicolumn{2}{|c|}{$\mathrm{HC}+\mathrm{NSF3}$} & \multicolumn{2}{|c|}{$\begin{array}{c}\mathrm{NSF} 3+\mathrm{CSE} \\
+\mathrm{HC}\end{array}$} & \multirow{2}{*}{ Total } \\
\hline & $\mathbf{N}$ & $\%$ & $\mathbf{N}$ & $\%$ & $\mathbf{N}$ & $\%$ & $\mathbf{N}$ & $\%$ & $\mathbf{N}$ & $\%$ & $\mathbf{N}$ & $\%$ & $\mathbf{N}$ & $\%$ & \\
\hline $\mathrm{SAH}$ & 93 & 69.4 & 1 & 100 & 1 & 33.3 & 30 & 42.3 & 1 & 50 & 23 & 67.6 & 27 & 56.3 & 176 \\
\hline DM & 7 & 5.2 & 0 & 0 & 1 & 33.3 & 8 & 11.3 & 0 & 0 & 2 & 5.9 & 5 & 10.4 & 23 \\
\hline $\mathrm{SAH}+\mathrm{DM}$ & 34 & 25.4 & 0 & 0 & 1 & 33.3 & 33 & 46.4 & 1 & 50 & 9 & 26.5 & 16 & 33.3 & 94 \\
\hline Total & 134 & $\begin{array}{r}100 \\
45.7\end{array}$ & 1 & $\begin{array}{l}100 \\
0.3\end{array}$ & 3 & $\begin{array}{c}100 \\
1\end{array}$ & 71 & $\begin{array}{r}100 \\
24.2\end{array}$ & 2 & $\begin{array}{l}100 \\
0.7\end{array}$ & 34 & $\begin{array}{r}100 \\
11.6\end{array}$ & 48 & $\begin{array}{c}100 \\
16.4\end{array}$ & 293 \\
\hline
\end{tabular}

Source: research data.

Tables 1 and 2 show the discrepancy between the total number of patients treated at the three levels of care $(\mathrm{N}=496)$ and the actual number of patients studied ( $N=293)$, since the same patient was examined in more than one level of care within the studied period.

Regarding care coordination (Table 2), it is possible to observe that, of a total of 455 patients registered at NSF3, according to data from SIAB 05/12/2008, 293 individuals (64.4\%) were treated within the last four years in one of the three public health units (NSF3, CSE or HC) and, of these, 134 (45.7\%) were treated at NSF3 and 287 (97.95\%) were being followed up at NSF3.

As for laboratory tests performed (Table 3), we observed that for 293 patients studied, 9,522 tests were requested (mean of 32.5 tests per patient), of which 568 tests were considered to be unnecessary (nearly 6\%), as they were requested outside the period recommended by the SMS protocol or for the same patient in two different care units of different levels, in close dates. The the reasons for which patients sought care in other units were not investigated. 
Table 3. Laboratory tests collected, percentage of spending with unnecessary tests for patients $(N=293)$ monitored between 2006 and 2009. Ribeirão Preto, São Paulo, Brazil, 2010.

\begin{tabular}{|c|c|c|c|c|c|}
\hline Type of test performed & TTP & TUT & TASR & TASUT & $\%$ SUT \\
\hline Urea & 427 & 25 & 789.9 & 46.2 & 5.8 \\
\hline Creatinine & 798 & 48 & $1,476.3$ & 88.8 & 6.0 \\
\hline Creatinine clearance & 25 & 1 & 87.7 & 3.5 & 4.0 \\
\hline Uric Acid & 315 & 19 & 582.7 & 35.1 & 6.0 \\
\hline Sodium & 507 & 30 & 937.9 & 55.5 & 5.9 \\
\hline Potassium & 552 & 33 & $1,021.2$ & 61.0 & 5.9 \\
\hline Urine I & 47 & 2 & 173.9 & 7.4 & 4.2 \\
\hline Chest radiography & 60 & 0 & 412.8 & 0 & 0 \\
\hline 24 hours proteinuria & 148 & 10 & 370.0 & 25.0 & 6.7 \\
\hline Microalbuminuria & 80 & 4 & 649.6 & 32.4 & 5.0 \\
\hline Fasting blood glucose & 1,129 & 66 & $2,088.6$ & 122.1 & 5.8 \\
\hline Post-prandial blood glucose & 384 & 29 & 710.4 & 53.6 & 7.5 \\
\hline $\begin{array}{l}\text { Glucose Tolerance Test (GTT) } \\
75 \mathrm{~g}\end{array}$ & 42 & 2 & 420.0 & 20.0 & 4.7 \\
\hline Glycohemoglobin & 500 & 32 & $3,930.0$ & 251.52 & 6.4 \\
\hline Fundus photograpy & 67 & 0 & 225.8 & 0 & 0 \\
\hline ECG & 188 & 2 & 968.2 & 10.3 & 1.0 \\
\hline Total cholesterol & 911 & 58 & $1,685.3$ & 107.3 & 6.3 \\
\hline $\mathrm{HDL}$ & 896 & 54 & $3,144.9$ & 189.54 & 6.0 \\
\hline Triglyceride & 850 & 59 & $2,983.5$ & 207.09 & 6.9 \\
\hline Aspartate transaminase (AST) & 389 & 26 & 781.8 & 52.26 & 6.6 \\
\hline Alanine transaminase (ALT) & 336 & 24 & 675.3 & 48.24 & 7.1 \\
\hline CPK & 246 & 19 & 905.2 & 69.92 & 7.7 \\
\hline Total bilirubin & 66 & 3 & 132.6 & 6.03 & 4.5 \\
\hline Direct bilirubin & 62 & 3 & 124.6 & 6.03 & 4.8 \\
\hline Indirect bilirubin & 42 & 0 & 84.4 & 0 & 0 \\
\hline Alkaline phosphatase & 66 & 2 & 132.6 & 4.0 & 3.0 \\
\hline Gamma-GT & 85 & 4 & 298.3 & 14.0 & 4.7 \\
\hline Amylase & 9 & 0 & 20.2 & 0 & 0 \\
\hline $\begin{array}{l}\text { Thyroid Stimulating Hormone } \\
\text { (TSH) }\end{array}$ & 194 & 10 & $1,738.2$ & 89.6 & 5.1 \\
\hline Free T4 & 49 & 3 & 568.4 & 34.8 & 6.1 \\
\hline Free T3 & 10 & 0 & 87.1 & 0 & 0 \\
\hline Total & 9,522 & 568 & $28,208.3$ & $1,641.5$ & 5.97 \\
\hline
\end{tabular}

Source: research data.

Legend: TTP = total number of tests performed, TUT = total number of unnecessary tests, TASR = total amount spent in Brazilian reais, TASUT = total amount spent with unnecessary tests = 49,364.53 dollars* $\%$ SUT = percentage of spending with unnecessary tests $=2,872.63$ dollars*. (conversion: 1 dollar $=1.75$ reais, December 2009)*

*http://economia.acspservicos.com.br/IEGV/IEGV_DOLAR.HTM 
Table 4. Relationship between requested and unnecessary tests, according to the place of treatment $(n=293)$, between 2006 and 2009. Ribeirão Preto, São Paulo, Brazil, 2010.

\begin{tabular}{lcccc} 
& NSF3 & CSE & HC & Total \\
\hline Requested tests & 4,555 & 2,821 & 2,146 & 9,522 \\
Unnecessary tests & 327 & 241 & - & 568 \\
$\begin{array}{l}\text { Percentage of unnecessary tests according to place of } \\
\text { treament }\end{array}$ & $7.17 \%$ & $8.54 \%$ & - & $5.97 \%$ \\
$\begin{array}{l}\text { Percentage of unnecessary tests, according to place of } \\
\text { treatment, in relation to total of unnecessary tests }\end{array}$ & $57.57 \%$ & $42.43 \%$ & - & $100 \%$ \\
\hline
\end{tabular}

Source: research data.

In terms of expenses, according to the Unified Health System costs table, resolution 10/2009 of SIGTAP/DATASUS (DATASUS, 2009), these 9,522 tests cost R\$28,208.28 to public funds, whereas the expense with 568 unnecessary exams was $\mathrm{R} \$ 1,641.58$, representing $5.97 \%$ of the total spending.

The most frequently requested tests were fasting blood glucose (nearly $11.9 \%$ of the total), creatinine (nearly $8.4 \%$ of the total), followed by total cholesterol, HDL and triglyceride $(9.6 \%, 9.4 \%$ and $9 \%$ respectively).

The most-requested ested unnecessary tests were CPK (creatine phosphokinase), post-prandial glucose and ALT (aspartate transaminase) (7.7\%, 7.5\% and $7.1 \%$ respectively), but the largest expenses, in terms of money, involved requests of glycohemoglobitriglyceride), trygliceride (R\$207.00), HDL (R\$ 189.50) and fasting blood glucose (R\$122.10).

According to Table 4, of the $5.97 \%$ of spending on unnecessary tests, NSF3 was responsible for nearly $58 \%$ of requests, against $42 \%$ of requests from CSE. In addition, of the 4,555 tests requested by NSF3, 7.17\% were unneeded, whereas in CSE, $8.54 \%$ of the 2,821 requested tests were redundant.unnecessary.

The absence of an information system that allows for the communication between health professionals at different levels - NSF3, CSE and HC (reference and counter-reference systems) contributed to the request of 5.97\% unnecessary complementary tests.

The results revealed that, within a health system with multidisciplinary services, there is still a lack of care comprehensiveness through a single clinical record, and this results in misallocation of resources and unnecessary spending.

\section{DISCUSSION}

The costs with complementary tests of 293 patients with diabetes and arterial hypertension of a reference unit in the east side of São Paulo was US\$ 49,364.53. According to a study conducted in Mexico ${ }^{(8)}$, laboratory tests for patients with DM is among the three highest costs, with a mean of US\$ 692.70 for patients hospitalized in an ICU, US\$ 396.80 in admission, US\$240.20 in the outpatient clinic, US\$218.60 in the emergency unit and US\$ 137.20 in the surgical center.

Another study carried out in São Paulo showed that $16.5 \%$ of the total cost with hypertensive patients corresponded to laboratory tests, totaling 66 million dollars, including drugs and consultations.(5) A study in Recife, Brazil, showed costs with hypertension drugs of R\$1,195,966, which represents $24.6 \%$ of the total cost. ${ }^{(9)}$

Arterial hypertension is considered to be a major public health problem, accounting for $45 \%$ of deaths resulting from heart diseases, totaling 9.4 million deaths over the world. Generally speaking, high-income countries have a lower incidence of hypertension (35\%) when compared to medium and low-income countries (40\%). In addition, as a result of inefficient or limited health systems, the number of people with undiagnosed, untreated or poorly controlled SAH is also higher in these locations. ${ }^{(10)}$

A study conducted in Recife analyzed the costs with care of DM and SAH patients, and the direct cost 
and the amount reimbursed by the SUS totaled RS 4,855,291.82 and $R \$ 2,118,893.56$, respectively. The items or services with the highest expenditures were: drugs (R\$ 1,762,424.42 - 36.3\%), third-party services (R\$ 996,637.82 - 20.5\%) and personnel (R\$978,096.10 - 20.1\%). All procedures had a higher estimate cost than the actual amounts paid by the SUS table.(9)

As a result of the growing concern with high costs in CNCS, studies are showing the great impact of costs with patients with diabetes and arterial hypertension. Most health systems are organized so as to provide care to isolated cases and in an unstructured manner, without focusing on coordinated and continuous care, which is essential for CNCS management.

For CNCS prevention and treatment, regardless of the level of care, it is paramount to have an adequate information system, as well as the broad consensus among health professionals, patients and family, in order to establish a "shared care" "(1:57-76) with the aim to achieve better quality and access to health care.

In this sense, some factors like overvaluation of laboratory tests to the detriment of physical examination or clinical history, defensive attitude of medical staff, professional insecurity or inexperience, shorter medical consultations, influence of media and conflicts of interest, lack of knowledge of procedures and lack of communication/integration between health services contributed to the growth of demand for complementary tests that help diagnosis and clinical treatment. ${ }^{(12)}$ However, medical recommendations must be based on the epidemiological situation and on regularly reviewed protocols ${ }^{(13)}$, thus preventing the excess of laboratory test requests, which are expensive and could be better used in health services. ${ }^{(12)}$

Therefore, in this context, the analyses of costs - whether they are related to materials, personnel, structure and/ or procedures - must result in streamlining and reducing costs, and also as a means of better using and prioritizing financial resources in order to achieve effectiveness of health care services.

\section{GINAL CONSIDERATIONS}

To search for new strategies of cost reduction, to lower the number of hospitalizations, to fight health issues and to achieve effectiveness of resources used in health services become the focus of health service managers; however, most CNCD programs basically focus on the disease and neglect care models that work in an integrated fashion and focus on patients' needs.

Therefore, the calculation of expenditures made the poor allocation of resources evident represents an important strategy to assess the CNCD care process, which is still influenced by the hospital-centered and biomedical mod$\mathrm{el}$, to the detriment of promotion of primary health care, which is the SUS gateway.

In that sense, in order to consolidate the principles of SUS, and considering the access and comprehensiveness of care services, it is necessary to organize integrated healthcare services by means of care networks that work in an articulated manner, with all levels involved, where reference and counter-reference systems are effective and strategic in the process of care management. These weaknesses, clearly shown throughout this study, suggest the need for further research and discussion of the subject in order to put in place the epistemological aspects that guide the SUS.

\section{REFERENCES}

1. Ministério da Saúde (BR), Secretaria de Atenção à Saúde, Departamento de Atenção Básica. Diretrizes para o cuidado das pessoas com doenças crônicas nas redes de atenção à saúde e nas linhas de cuidado prioritária. Brasília; 2013.

2. Bloom DE, Cafiero ET, Jané-Llopis E, Abrahams-Gessel S, Bloom LR, Fathima $S$, et al. The global economic burden of non-communicable diseases. Geneva: World Economic Forum; 2011.

3. Federação Internacional de Diabetes. Atlas de la diabetes de la FID [Internet]. 5. ed. Brussels; 2012 [citado 2013 mar 03]. Disponível em: www.idf.org/diabetesatlas.

4. Organización Mundial de Salud. Estadísticas sanitarias mundiales: una instantánea de la salud mundial [Internet] Ginebra; 2012 [citado 2013 mar 03]. Disponível em: http://apps.who.int/iris/bitstream/10665/44858/1/9789243564449_ spa.pdf?ua=1

5. Dib MW, Riera R, Ferraz MB. Estimated annual cost of arterial hypertension treatment in Brazil. Rev Panam Salud Publica. 2010;27(2):125-31.

6. Santos IS, Victora CG. Serviços de saúde: epidemiologia, pesquisa e avaliação. Cad Saúde Pública 2004; 20 Suppl 2:337-41.

7. Ministério da Saúde (BR), Secretaria de Atenção à Saúde, Departamento de Atenção Básica. Diabetes mellitus. Brasília, 2006. Cadernos de Atenção Básica, 16.

8. Rodríguez BRA, Reynales SLM, Jiménez RJA, Juárez MSA, Hernández AM. Costos directos de atención médica en pacientes con diabetes mellitus tipo 2 en México: análisis de microcosteo. Rev Panam Salud Publica. 2010;28(6):41220.

9. Marinho MGS, Cesse EAP, Bezerra AFBB, Carvalho IM, Fontbonne A, Carvalho EF. Análise de custos da assistência à saúde aos portadores de diabetes melito e hipertensão arterial em uma unidade de saúde pública de referência em Recife - Brasil. Arq Bras Endocrinol Metab. 2011;55(6):406-11. 
10. World Health Organization. A global brief on hypertension: world health day 2013 [Internet]. Geneva; 2013 [citado 2013 abr 05]. Disponível em: http://apps.who. int/iris/bitstream/10665/79059/1/WHO_DCO_WHD_2013.2_eng.pdf?ua=1

11. Casajuana-Brunet J. Cordinación entre atención primaria y atención especializada. In: Casajuana-Brunet J. Gestión del día a día en el equipo de atención primaria. Barcelona: SEMFYC Ediciones; 2007. p. 57-76.
12. Aguiar FJB, Ferreira-Júnior M, Sales MM, Cruz-Neto LM, Fonseca LAM, Sumita NM, et al. Proteína C reativa: aplicações clínicas e propostas para utilização racional. Rev Assoc Med Bras [Internet]. 2013 [citado 2013 out 27];59(1):8592.

13. Moura A, Viriato A. Gestão hospitalar: da organização ao serviço de apoio diagnóstico e terapêutico. Barueri: Manole; 2008. p.105.

\section{Author's address:}

Marli de Carvalho Jericó

Rua Benjamin Constant, 4035/91, Vila Imperial

15015-600, São José do Rio Preto, SP

E-mail: marli@famerp.br
Received: 25.01.2014

Approved: 29.10.2014 